\title{
A Study of Anonic Motions in Solid Rubidium and Cesium Tetrachloroaurates(III) by Measuring the Temperature Dependence of Chlorine Nuclear Quadrupolar Relaxation Times
}

\author{
Atsushi Ishikawa, Tetsuo Asaji, and Daiyu Nakamura \\ Department of Chemistry, Faculty of Science, Nagoya University, Chikusa, Nagoya 464-01, Japan \\ Ryuichi Ikeda \\ Institute for Molecular Science, Myodaiji, Okazaki 444, Japan
}

Z. Naturforsch. 44a, 125-130 (1989); received December 10, 1988

The temperature dependences of ${ }^{35} \mathrm{Cl} \mathrm{NQR}$ frequencies and ${ }^{35} \mathrm{Cl}$ nuclear quadrupolar relaxation times $T_{1 \mathrm{Q}}$ and $T_{2 \mathrm{Q}}$ were determined above $82 \mathrm{~K}$ for $\mathrm{Rb}\left[\mathrm{AuCl}_{4}\right]$ and $\mathrm{Cs}\left[\mathrm{AuCl}_{4}\right]$ up to ca. 340 and $320 \mathrm{~K}$, respectively. Below these temperatures two ${ }^{35} \mathrm{Cl} \mathrm{NQR}$ frequencies were observed for each complex whereas no resonance could be detected above the respective temperatures. For both complexes, $T_{1 \mathrm{Q}}$ observed below ca. $270 \mathrm{~K}$ was interpreted as mainly determined by the rotary lattice vibration around the pseudo- $\mathrm{C}_{4}\left(\mathrm{C}_{4}^{\prime}\right)$ axis and each $\mathrm{Cl}-\mathrm{Au}-\mathrm{Cl}$ diagonal axis of the square planar complex anion, whereas $T_{1}$ observed above ca. $270 \mathrm{~K}$ was definitely shown to be determined through the reorientation of the anions about their $\mathrm{C}_{4}^{\prime}$ axis. The activation energies for the $\mathrm{C}_{4}^{\prime}$ reorientation of the anions was evaluated to be 71 and $53 \mathrm{~kJ} \mathrm{~mol}^{-1}$ for the rubidium and cesium salts, respectively. The anionic dynamics are discussed by assuming the motion of the anions within and out of the $\mathrm{C}_{4}$ potential wells at lower and higher temperatures, respectively.

\section{Introduction}

Previously, we investigated the temperature variation of the chlorine nuclear quadrupolar spin-lattice relaxation time $T_{1 \mathrm{Q}}$ of pyridinium tetrachloroaurate(III), pyH $\left[\mathrm{AuCl}_{4}\right]$, and found that the pseudohexad $\left(\mathrm{C}_{6}^{\prime}\right)$ reorientation of $\mathrm{pyH}^{+}$ions about their $\mathrm{C}_{6}^{\prime}$ axes and the pseudotetrad $\left(\mathrm{C}_{4}^{\prime}\right)$ reorientation of the complex anions about their $\mathrm{C}_{4}^{\prime}$ axes play an important role for the determination of $T_{1 \mathrm{Q}}$ in the temperature regions below ca. $350 \mathrm{~K}$ and above $360 \mathrm{~K}$, respectively [1]. The activation energy for the $\mathrm{C}_{4}^{\prime}$ anionic reorientation was evaluated as $67 \mathrm{~kJ} \mathrm{~mol}^{-1}$. For this complex, the chlorine quadrupolar relaxation resulting from lattice vibrations involving the complex anions was not detectable. The temperature dependence of chlorine $T_{1 \mathrm{Q}}$ has also been observed for guanidinium tetrachloroaurate(III), guH $\left[\mathrm{AuCl}_{4}\right]$ [2]. In this complex, it was concluded that the $\mathrm{C}_{4}^{\prime}$ reorientation and the rotary lattice vibration of the complex anions are responsible for the determination of the chlorine $T_{1 \mathrm{Q}}$ in the high- and low-temperature regions, respective-

Reprint requests to Prof. Daiyu Nakamura, Department of Chemistry, Nagoya University, Nagoya 464-01, Japan. ly. The same activation energy for the $\mathrm{C}_{4}^{\prime}$ reorientation of the anions as that of $\mathrm{pyH}\left[\mathrm{AuCl}_{4}\right]$ was accidentally obtained for this complex.

For the above complexes one can assume that the hindrance barrier to the $\mathrm{C}_{4}^{\prime}$ reorientation of the complex anion arises mainly from $\mathrm{N}-\mathrm{H} \ldots \mathrm{Cl}$ type $\mathrm{H}$-bond formation between the cations and the complex anion. To definitely clarify the above point and also to investigate the ionic dynamics of the square planar $\left[\mathrm{AuCl}_{4}\right]^{-}$anions in the crystal, the present study has been carried out for solid $\mathrm{Rb}\left[\mathrm{AuCl}_{4}\right]$ and $\mathrm{Cs}\left[\mathrm{AuCl}_{4}\right]$ by measuring the temperature dependence of ${ }^{35} \mathrm{Cl} \mathrm{NQR}$ frequencies and the chlorine $T_{1 \mathrm{Q}}$ as well as the chlorine spin-spin relaxation time $T_{2 \mathrm{Q}}$.

\section{Experimental}

A homemade pulsed NQR spectrometer already described [3, 4] was employed for the observation of the spin-echo signals arising from ${ }^{35} \mathrm{Cl}$ nuclei in the samples. $T_{1 \mathrm{Q}}$ and $T_{2 \mathrm{Q}}$ were measured by use of $\pi / 2-\tau-\pi / 2-\tau_{\mathrm{e}}-\pi$ and $\pi / 2-\tau-\pi$ pulse sequences, respectively, where the spacing time $\tau$ was varied and $\tau_{\mathrm{e}}$ was set constant at ca. $150 \mu$ s throughout the measurements. The echo amplitude decreased exponentially in the

0932-0784/89/0200-0125\$01.30/0. - Please order a reprint rather than making your own copy. 
$T_{1 \mathrm{Q}}$ measurements. However, for $T_{2 \mathrm{Q}}$ it evolved as a Gaussian-type function in a region of $\tau<1 \mathrm{~ms}$. For $\tau>1 \mathrm{~ms}$ the decay was much slower than Gaussian-type. The values of $T_{2 \mathrm{Q}}$ were estimated from the Gaussian-type decay signals by fitting their initial portion to the relation

$$
M=M_{0} \exp \left\{-\left(2 \tau / T_{2 \mathrm{Q}}\right)^{2}\right\} .
$$

Here, $M$ and $M_{0}$ indicate the amplitude of echo signals for the spacing time $\tau$ and $\tau=0$, respectively. The sample temperature was controlled within $\pm 0.5 \mathrm{~K}$ by employing a temperature controller described elsewhere [3], and was determined by use of a copper constantan thermocouple. The observed temperatures were estimated to be accurate within $\pm 1 \mathrm{~K}$. Fourier transformed (FT) NQR spectra were calculated with a usual computation program [5] from 8192 accumulated echo signals at maximum.

The samples were prepared by adding rubidium or cesium chlorides to a hot hydrochloric acid solution of tetrachloroauric acid and slowly cooling the solution [6]. The yellow needle-shaped crystals obtained for both complexes were filtered off and dried in a desiccator. For the cesium salt, the crystallization water was completely removed by pumping at ca. $80^{\circ} \mathrm{C}$. To obtain good signal-to-noise ratios for the NQR spinecho signals, the crystals thus obtained were annealed at $80^{\circ} \mathrm{C}$ for $20 \mathrm{~h}$. The samples were identified by observing the NQR signals of ${ }^{35} \mathrm{Cl}$ nuclei at the frequencies reported [7].

\section{Results}

\section{Chlorine NQR Frequencies}

The temperature dependence of the ${ }^{35} \mathrm{Cl}$ NQR frequencies determined from the spin-echo signals of $\mathrm{Rb}\left[\mathrm{AuCl}_{4}\right]$ and $\mathrm{Cs}\left[\mathrm{AuCl}_{4}\right]$ is shown in Fig. 1, and the values evaluated at various temperatures are given in Table 1. The resonance frequencies observed agree well with those reported by Sasane et al. [7].

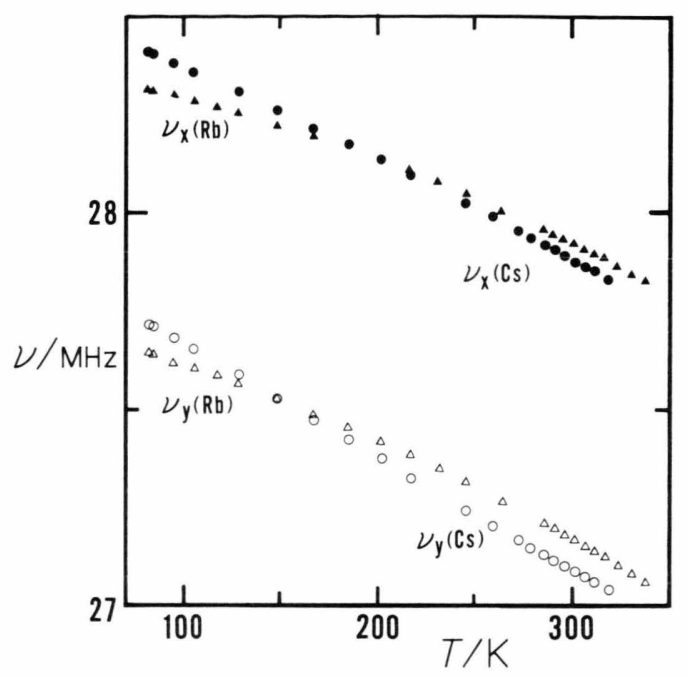

Fig. 1. Temperature dependences of the ${ }^{35} \mathrm{Cl} \mathrm{NQR}$ frequencies $v_{x}(\mathrm{Rb})(\mathbf{\Delta})$ and $v_{v}(\mathrm{Rb})(\Delta)$ determined for $\mathrm{Rb}\left[\mathrm{AuCl}_{4}\right]$, and $v_{x}(\mathrm{Cs})(\bullet)$ and $v_{y}(\mathrm{Cs})(\mathrm{O})$ for $\mathrm{Cs}\left[\mathrm{AuCl}_{4}\right]$.

\begin{tabular}{|c|c|c|c|c|c|c|c|}
\hline \multicolumn{4}{|c|}{$\mathrm{Rb}\left[\mathrm{AuCl}_{4}\right]$} & \multicolumn{4}{|c|}{$\mathrm{Cs}\left[\mathrm{AuCl}_{4}\right]$} \\
\hline$T / \mathrm{K}$ & $v / \mathrm{MHz}$ & $T_{1 \mathrm{Q}} / \mathrm{ms}$ & $T_{2 \mathrm{Q}} / \mathrm{ms}^{\mathrm{a}}$ & $T / \mathrm{K}$ & $v / \mathrm{MHz}$ & $T_{1 \mathrm{Q}} / \mathrm{ms}$ & $T_{2 \mathrm{Q}} / \mathrm{ms}^{\mathrm{a}}$ \\
\hline \multirow[t]{2}{*}{82} & 28.316 & 670 & 1.7 & 82 & 28.411 & 265 & - \\
\hline & 27.645 & 840 & 1.6 & & 27.717 & 345 & - \\
\hline \multirow[t]{2}{*}{118} & 28.270 & 290 & 1.7 & 129 & 28.307 & 98 & 1.6 \\
\hline & 27.587 & 360 & 1.6 & & 27.590 & 114 & 1.6 \\
\hline \multirow[t]{2}{*}{129} & 28.255 & 250 & - & 186 & 28.175 & 43 & 1.6 \\
\hline & 27.567 & 320 & - & & 27.423 & 52 & 1.7 \\
\hline \multirow{2}{*}{149} & 28.224 & 180 & 1.6 & 246 & 28.025 & 20 & 1.8 \\
\hline & 27.528 & 230 & 1.7 & & 27.244 & 23 & 1.7 \\
\hline \multirow[t]{2}{*}{246} & 28.049 & 46 & - & 273 & 27.955 & 7.2 & 1.5 \\
\hline & 27.315 & 56 & - & & 27.168 & 6.9 & 1.6 \\
\hline \multirow[t]{2}{*}{301} & 27.921 & 6.8 & - & 286 & 27.920 & 2.8 & 1.2 \\
\hline & 27.169 & 6.6 & - & & 27.133 & 3.0 & 1.3 \\
\hline \multirow[t]{2}{*}{306} & 27.908 & 4.1 & 1.4 & 296 & 27.894 & 1.6 & 0.95 \\
\hline & 27.155 & 4.3 & 1.4 & & 27.103 & 1.7 & 0.87 \\
\hline \multirow{2}{*}{323} & 27.864 & 0.92 & 0.95 & 311 & 27.855 & 0.42 & 0.54 \\
\hline & 27.104 & 0.94 & 0.97 & & 27.063 & 0.50 & 0.52 \\
\hline \multirow[t]{2}{*}{330} & 27.844 & 0.57 & 0.66 & & & & \\
\hline & 27.082 & 0.54 & 0.61 & & & & \\
\hline
\end{tabular}

Table $1 .{ }^{35} \mathrm{Cl}$ NQR frequencies $v$, spin-lattice relaxation times $T_{10}$, and spin-spin relaxation times $T_{2 \mathrm{O}}$ observed for $\mathrm{Rb}\left[\mathrm{AuCl}_{4}\right]$ and $\mathrm{Cs}\left[\mathrm{AuCl}_{4}\right]$ at several temperatures.

\footnotetext{
a Dashes indicate no measurements carried out.
} 
Two resonance lines of the ${ }^{35} \mathrm{Cl}$ nuclei were observed for each complex. Hereafter they are denoted as $v_{x}(\mathrm{Rb})$ and $v_{y}(\mathrm{Rb})$ for the high- and low-frequency lines of $\mathrm{Rb}\left[\mathrm{AuCl}_{4}\right]$, respectively, and analogously as $v_{x}(\mathrm{Cs})$ and $v_{y}(\mathrm{Cs})$ for the $\mathrm{Cs}\left[\mathrm{AuCl}_{4}\right]$ lines. For both complexes the temperature dependence of the $v_{y}$ lines was slightly steeper than that of the respective $v_{x}$ lines. The temperature dependence of $v_{x}(\mathrm{Cs})$ and $v_{y}(\mathrm{Cs})$ was steeper than that of $v_{x}(\mathrm{Rb})$ and $v_{y}(\mathrm{Rb})$. Above room temperature the echo signals of both complexes became gradually weak and faded out at ca. 340 and $320 \mathrm{~K}$ for both lines of $\mathrm{Rb}\left[\mathrm{AuCl}_{4}\right]$ and $\mathrm{Cs}\left[\mathrm{AuCl}_{4}\right]$, respectively.

\section{Chlorine $T_{1 Q}$ and $T_{2 Q}$}

The temperature dependence of chlorine $T_{1 \mathrm{Q}}$ and $T_{2 \mathrm{Q}}$ for two resonance lines of both complexes observed between ca. 80 and $340 \mathrm{~K}$ are shown in Fig. 2, and the numerical values obtained at some temperatures are given in Table 1.

When the samples were warmed from $82 \mathrm{~K}$ to ca. $270 \mathrm{~K}$, the ${ }^{35} \mathrm{Cl} T_{1 \mathrm{Q}}$ values of both complexes decreased gradually with increasing temperature and can be expressed by

$$
T_{1 \mathrm{Q}} \propto T^{-n} \text {. }
$$

The exponents $\mathrm{n}$ for the $v_{x}(\mathrm{Rb}), v_{y}(\mathrm{Rb}), v_{x}(\mathrm{Cs})$, and $v_{y}(\mathrm{Cs})$ lines were $2.0,2.3,2.0$, and $2.3( \pm 0.2)$, respectively.

When the temperature increased furthermore from ca. $270 \mathrm{~K}$, the $v_{x}$ and $v_{y}$ lines of each complex gave almost the same $T_{1 \mathrm{Q}}$ at a given temperature, and all the $T_{1 \mathrm{Q}}$ decreased rapidly. The temperature dependence of $T_{1 \mathrm{Q}}$ for the two lines of each complex above ca. $270 \mathrm{~K}$ can expressed as

$$
\log T_{1 \mathrm{Q}} \propto T^{-1} .
$$

The values of ${ }^{35} \mathrm{Cl} T_{2 Q}$ for all resonance lines studied were temperature independent between ca. 80 and $280 \mathrm{~K}$, having the same value of $1.7 \mathrm{~ms}$ as indicated in Figure 2. Above ca. $280 \mathrm{~K}$, the $T_{2 Q}$ values observed for the respective complexes decreased rapidly with increasing temperature, and the $T_{1 \mathrm{Q}}$ and $T_{2 \mathrm{Q}}$ values became almost the same at a given temperature above ca. $310 \mathrm{~K}$.

\section{FT NQR Spectra}

Sasane et al. [7] reported that the resonance linewidth of $v_{y}(\mathrm{Cs})$ was broader than that of $v_{x}(\mathrm{Cs})$ and

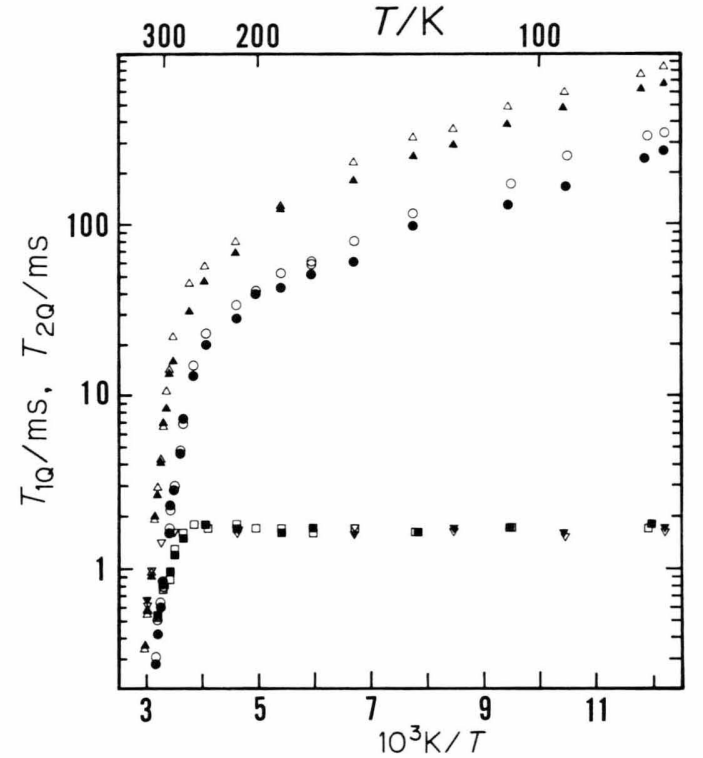

Fig. 2. The temperature dependences of nuclear quadrupole spin-lattice relaxation times $T_{10}$ and spin-spin relaxation times $T_{20}$ for the ${ }^{35} \mathrm{Cl}$ NQR lines $v_{x}(\mathrm{Rb})$ and $v_{y}(\mathrm{Rb})$ of $\mathrm{Rb}\left[\mathrm{AuCl}_{4}\right]$, and $v_{x}(\mathrm{Cs})$ and $v_{y}(\mathrm{Cs})$ of $\mathrm{Cs}\left[\mathrm{AuCl}_{4}\right]$. The $T_{10}$ values are indicated by $\Delta, \Delta, \bullet$, and $\circ$ for $v_{x}(\mathrm{Rb}), v_{y}(\mathrm{Rb})$, $v_{x}(\mathrm{Cs})$, and $v_{y}(\mathrm{Cs})$, respectively. The $T_{2 \mathrm{Q}}$ values are indicated by $\mathbf{\nabla}, \nabla, \boldsymbol{\square}$, and $\square$ for the NQR lines in the same order.

both linewidths suddenly decreased with increasing temperature between 247 and $258 \mathrm{~K}$ for $v_{x}(\mathrm{Cs})$ and between 258 and $263 \mathrm{~K}$ for $v_{y}(\mathrm{Cs})$. These experiments were performed with a superregenerative spectrometer, which is not a reliable means for the determination of NQR line shapes. Therefore we reinvestigated the line shape of the two ${ }^{35} \mathrm{Cl}$ NQR lines of $\mathrm{Cs}\left[\mathrm{AuCl}_{4}\right]$ at various temperatures by recording FT NQR spectra. The spectra obtained at several temperatures are shown in Figure 3. The linewidths for $v_{x}(\mathrm{Cs})$ and $v_{y}(\mathrm{Cs})$ recorded were almost the same and independent of temperature, in disagreement with the results of Sasane et al. previously reported [7]. This is presumably because they measured the linewidths with the sample including a small amount of water.

\section{Discussion}

$\mathrm{Rb}\left[\mathrm{AuCl}_{4}\right]$ and $\mathrm{Cs}\left[\mathrm{AuCl}_{4}\right]$ are known to be isomorphous at room temperature $[8,9]$, forming monoclinic crystals belonging to the space group I $2 / \mathrm{c}$ with $Z=4$ [9]. The four complex anions in a unit cell are crystal- 


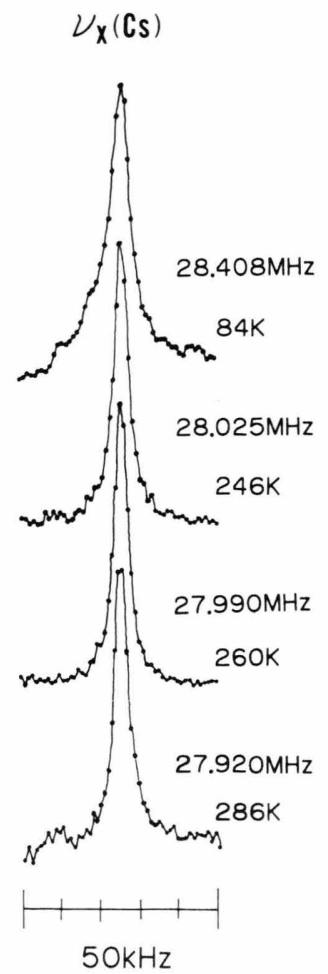

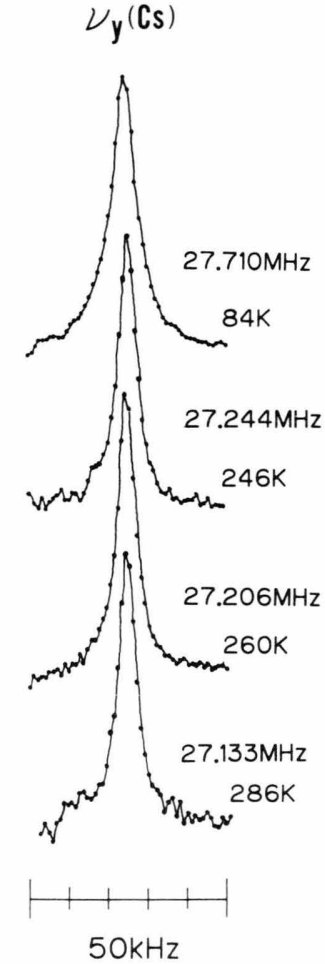

Fig. 3. Fourier transform NQR spectra for $v_{x}(\mathrm{Cs})$ and $v_{y}(\mathrm{Cs})$ lines at several temperatures.

lographically equivalent, and each anion forms a slightly deformed square involving two kinds of nonequivalent chlorines, the equivalent ones of which are located at trans positions. Accordingly, $v_{x}$ and $v_{y}$ can be attributed to be two kinds of chlorines in the $\left[\mathrm{AuCl}_{4}\right]^{-}$anion. For both complexes $v_{x}$ is higher than $v_{y}$ by ca. $0.7 \mathrm{MHz}$. This may be too large to be attributable to the lattice effect. Therefore, the chlorines showing $v_{x}$ can be considered to have a slightly shorter $\mathrm{Au}-\mathrm{Cl}$ bond length than the others in the anion (by $0.01 \AA$ for the rubidium salt [9]) [10].

For the present complexes, $T_{2 \mathrm{Q}}$ is thought to be determined mainly by magnetic dipolar interactions between chlorine nuclei as in the case of $\mathrm{K}_{2} \mathrm{PtCl}_{6}$ [11]. The $T_{2 \mathrm{Q}}$ values for the chlorines exhibiting $v_{x}(\mathrm{Rb})$, $v_{y}(\mathrm{Rb}), v_{x}(\mathrm{Cs})$, and $v_{y}(\mathrm{Cs})$ were almost the same at a given temperature in a temperature range studied. This means that the strength of dipolar interactions is approximately the same for both complexes, consisting with the assumption of pseudosquare-planar complex anions of nearly the same size. This is supported by the fact that both complexes give NQR frequencies very near to each other at a given temperature in the
A. Ishikawa et al. - Anionic Motions in Solid Rb and Cs

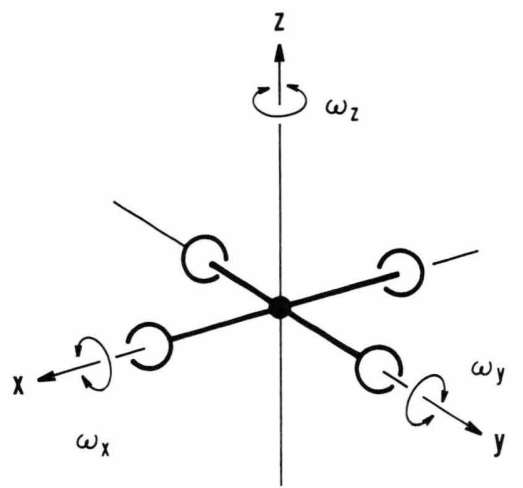

Fig. 4. The coordinate system for the $\left[\mathrm{AuCl}_{4}\right]^{-}$anion used in the text. Solid and open circles indicate $\mathrm{Au}$ and $\mathrm{Cl}$ atoms, respectively.

whole temperature range where observation was made. In the following discussion we assume that the moments of inertia of the $\left[\mathrm{AuCl}_{4}\right]^{-}$anions around the respective principal axes are equal to each other between both complexes.

\section{$T_{1 Q}$ in the High-Temperature Region}

Above ca. $270 \mathrm{~K}$, each complex gave the same $T_{1 \mathrm{O}}$ temperature dependence for the $v_{x}$ and $v_{y}$ lines and the exponential decrease of $T_{1 \mathrm{Q}}$ with decreasing $T^{-1}$ suggests that $T_{1 \mathrm{Q}}$ of these complexes results from sudden but infrequent jumps of the spin quantization axis of the chlorine nuclei in the complex anions [12]. As the most probable candidate for this motion we assume a $90^{\circ}$ reorientational jump of the pseudosquare-planar anion about its $\mathrm{C}_{4}^{\prime}$ axis. Here, we employ the coordinate system given in Fig. 4 for the anion. The chlorines placed on the $x$-and $y$-axis are defined to give $v_{x}$ and $v_{y}$ lines, respectively.

According to the foregoing relaxation mechanism, the temperature dependence of $T_{1 \mathrm{Q}}$ can be expressed [2] as

$$
T_{1 \mathrm{Q}}\left(v_{x}\right)=T_{1 \mathrm{Q}}\left(v_{y}\right)=(2 / 3) \tau=(2 / 3) \tau_{0} \exp \left(E_{\mathrm{a}} / R T\right) .
$$

Here, $\tau$ and $E_{\mathrm{a}}$ denote the correlation time and the activation energy for the present motion, respectively. $\tau$ was assumed to be expressed by the Arrhenius relationship, where $\tau_{0}$ indicates the correlation time at the limit of infinite temperature. Using (4), $E_{\mathrm{a}}$ can be evaluated from the gradient of the observed $\log T_{1 \mathrm{Q}}$ vs. $T^{-1}$ plots. The $E_{\mathrm{a}}$ values obtained for both complexes are listed in Table 2 together with other $\left[\mathrm{AuCl}_{4}\right]^{-}$salts for comparison. 
Table 2. The activation energy $E_{\mathrm{a}}$ for the $90^{\circ}$ reorientational motion of $\left[\mathrm{AuCl}_{4}\right]^{-}$anions.

\begin{tabular}{lll}
\hline Compound & $E_{\mathrm{a}} / \mathrm{kJ} \mathrm{mol}^{-1}$ & Ref. \\
\hline $\mathrm{guH}\left[\mathrm{AuCl}_{4}\right]$ & 67 & {$[2]$} \\
pyH $\left[\mathrm{AuCl}_{4}\right]$ & 67 & {$[1]$} \\
$\mathrm{Cs}\left[\mathrm{AuCl}_{4}\right]$ & 53 & present work \\
$\mathrm{Rb}\left[\mathrm{AuCl}_{4}\right]$ & 71 & present work \\
$\mathrm{NH}_{4}\left[\mathrm{AuCl}_{4}\right]$ & 80 & {$[13]$} \\
\hline
\end{tabular}

The $E_{\mathrm{a}}$ values for the cesium, rubidium, and ammonium tetrachloroaurates(III) [13] increase with decreasing ionic radii of the cations [14]. The guanidinium [2] and pyridinium [1] tetrachloroaurates(III) showed nearly the same $E_{\mathrm{a}}$ value as that of the rubidium salt, although these two cations can form $\mathrm{N}-\mathrm{H} \ldots \mathrm{Cl}$ type $\mathrm{H}$-bonds in the crystals. Generally speaking, ammonium ions also have a possibility to form $\mathrm{N}-\mathrm{H} \ldots \mathrm{Cl}$ type $\mathrm{H}$-bonds. However, the ammonium ion in $\mathrm{NH}_{4}\left[\mathrm{AuCl}_{4}\right]$ is considered to be almost free from such interaction because the very low activation energy of $4 \mathrm{~kJ} \mathrm{~mol}^{-1}$ was estimated from the ${ }^{1} \mathrm{H}$ NMR experiments for the cationic reorientation in $\mathrm{NH}_{4}\left[\mathrm{AuCl}_{4}\right]$ crystals [15]. From the $E_{\mathrm{a}}$ data listed in Table 2 we can conclude that $E_{\mathrm{a}}$ for the motion of the anion in the present complexes is mainly determined by the packing scheme of the ions in the crystals, and $\mathrm{N}-\mathrm{H} \ldots \mathrm{Cl}$ type $\mathrm{H}$-bonding in the guanidinium and pyridinium salts does not give appreciable effect on $E_{\mathrm{a}}$.

\section{$T_{10}$ in Low-Temperature Region}

Below ca. $270 \mathrm{~K}$ the temperature dependence of $T_{10}$ is approximately proportional to $T^{-2}$. This suggests that the rotary lattice vibration of the complex anions is responsible for the relaxation process [16]. When quadrupolar relaxation is governed by lattice vibrations involving the nuclei in question, the temperature dependence of $T_{1 \mathrm{Q}}^{-1}$ for the nuclear spin $I$ equal to $3 / 2$ is given by the following equation at high temperatures under the harmonic oscillator approximation for the vibration $[17,18]$ :

$$
T_{1 \mathrm{Q}}^{-1}=\sum_{l}\left(12 k^{2} \omega_{Q}^{2} / \hbar I_{l} \tau_{\mathrm{g}}\right)\left(T^{2} / \omega_{l}^{5}\right)(1+\gamma) .
$$

Here, $\omega_{l}, I_{l}$, and $\tau_{\mathrm{g}}$ are the $l$-th librational angular frequency of the complex anion, the moment of inertia for the $l$-th librational axis, and the mean residence time of the anion in the ground state of the libration, respectively. The NQR angular frequency is indicated by $\omega_{\mathrm{Q}}$, and $\gamma$ is equal to the ratio $W_{2} / W_{1}$, where $W_{1}$ and $W_{2}$ indicate the transition probabilities of the quadrupole interaction system with the selection rule $\Delta m_{\mathrm{I}}= \pm 1$ and $\Delta m_{\mathrm{I}}= \pm 2$, respectively. In (5), a cylindrically symmetric electric field gradient is assumed for the chlorines of the anion. $\tau_{\mathrm{g}}$ and $\gamma$ are assumed to be constant, independent of the librational modes.

Taking the librational oscillations about the $x, y$, and $z$ axes shown in Fig. 4 into account, $T_{1 \mathrm{Q}}^{-1}$ for $v_{x}$ and $v_{y}$ can be written as

$$
\begin{aligned}
& T_{1 \mathrm{Q}}^{-1}\left(v_{x}\right) \propto\left(v_{x}^{2} / I_{z}\right)\left[1+\left(I_{z} / I_{y}\right)\left(\omega_{z} / \omega_{y}\right)^{5}\right]\left(T^{2} / \omega_{z}^{5}\right), \\
& T_{1 \mathrm{Q}}^{-1}\left(v_{y}\right) \propto\left(v_{y}^{2} / I_{z}\right)\left[1+\left(I_{z} / I_{x}\right)\left(\omega_{z} / \omega_{x}\right)^{5}\right]\left(T^{2} / \omega_{z}^{5}\right) .
\end{aligned}
$$

Accordingly, the ratio $T_{1 \mathrm{Q}}^{-1}\left(v_{x}\right) / T_{1 \mathrm{Q}}^{-1}\left(v_{y}\right)$ at a given temperature becomes

$$
T_{1 \mathrm{Q}}^{-1}\left(v_{x}\right) / T_{1 \mathrm{Q}}^{-1}\left(v_{y}\right)=\left(v_{x} / v_{y}\right)^{2} \cdot \frac{\left[1+\left(I_{z} / I_{y}\right)\left(\omega_{z} / \omega_{y}\right)^{5}\right]}{\left[1+\left(I_{z} / I_{x}\right)\left(\omega_{z} / \omega_{x}\right)^{5}\right]}
$$

For both complexes, $T_{1 \mathrm{Q}}$ was observed to be shorter for $v_{x}$ than $v_{y}$ at lower temperatures. For example, the experimentally determined value of $T_{1 \mathrm{Q}}^{-1}\left(v_{x}\right) / T_{1 \mathrm{Q}}^{-1}\left(v_{y}\right)$, for $\mathrm{Rb}\left[\mathrm{AuCl}_{4}\right]$ was 1.3 at $82 \mathrm{~K}$. Since $\left(v_{x} / v_{y}\right)^{2}=1.05$ at $82 \mathrm{~K}$ and $I_{x} / I_{y}=1.007$, the value of which can be calculated by use of the atomic coordinates reported by Strähle and Bärnighausen [9], the difference observed between $T_{1 \mathrm{Q}}\left(v_{x}\right)$ and $T_{1 \mathrm{Q}}\left(v_{y}\right)$ should be attributed to the difference between the librational frequencies $\omega_{x}$ and $\omega_{y}$.

The $T_{1 \mathrm{Q}}^{-1}$ ratio of the $v_{x}$ lines of $\mathrm{Rb}\left[\mathrm{AuCl}_{4}\right]$ and $\mathrm{Cs}\left[\mathrm{AuCl}_{4}\right]$ at a given temperature, $T_{1 \mathrm{Q}}^{-1}\left(v_{x \mathrm{C}}\right) / T_{1 \mathrm{Q}}^{-1}\left(v_{x \mathrm{R}}\right)$, can be written as

$$
\begin{aligned}
& T_{1 \mathrm{Q}}^{-1}\left(v_{x \mathrm{C}}\right) / T_{1 \mathrm{Q}}^{-1}\left(v_{x \mathrm{R}}\right) \\
& =\left(v_{x \mathrm{C}} / v_{x \mathrm{R}}\right)^{2} \frac{I_{z \mathrm{R}}\left[1+\left(I_{z \mathrm{C}} / I_{y \mathrm{C}}\right)\left(\omega_{z \mathrm{C}} / \omega_{y \mathrm{C}}\right)^{5}\right]}{I_{z \mathrm{C}}\left[1+\left(I_{z \mathrm{R}} / I_{y \mathrm{R}}\right)\left(\omega_{z \mathrm{R}} / \omega_{y \mathrm{R}}\right)^{5}\right]}\left(\omega_{z \mathrm{R}} / \omega_{z \mathrm{C}}\right)^{5} .
\end{aligned}
$$

Here, the subscripts $\mathrm{C}$ and $\mathrm{R}$ represent the physical quantities belonging to the $\mathrm{Cs}$ and $\mathrm{Rb}$ salts, respectively. Since $I_{l}(\mathrm{Cs}) \simeq I_{l}(\mathrm{Rb})$ for $l=x, y$, and $z$ discussed above, and also $v_{x \mathrm{C}} \simeq v_{x \mathrm{R}}$, the following equation can be derived provided the ratio of $\omega_{z} / \omega_{y}$ is unchanged for both complexes:

$$
\left(\omega_{z \mathrm{R}} / \omega_{z \mathrm{C}}\right)=\left[T_{1 \mathrm{Q}}^{-1}\left(v_{x \mathrm{C}}\right) / T_{1 \mathrm{Q}}^{-1}\left(v_{x \mathrm{R}}\right)\right]^{1 / 5} .
$$

From the $T_{1 \mathrm{Q}}$ values of $\mathrm{Rb}\left[\mathrm{AuCl}_{4}\right]$ and $\mathrm{Cs}\left[\mathrm{AuCl}_{4}\right]$ observed for the $v_{x}$ lines at $82 \mathrm{~K}$, the ratio of $\left(\omega_{z \mathrm{R}} / \omega_{z \mathrm{C}}\right)$ was obtained as 1.2 using (10). This means that the librational frequency of the anion in crystals about the $\mathrm{C}_{4}^{\prime}$ axis is larger for $\mathrm{Rb}\left[\mathrm{AuCl}_{4}\right]$ than for $\mathrm{Cs}\left[\mathrm{AuCl}_{4}\right]$. 
The above results can be confirmed by applying a simple potential curve $V$ approximated to have the $\mathrm{C}_{4}$ symmetry for the in-plane $\mathrm{C}_{4}^{\prime}$ reorientation of the anion. Her. we assume that $V$ can be expressed as

$$
V=(1 / 2) V_{0}(1-\cos 4 \phi),
$$

where $V_{0}$ and $\phi$ are the barrier height of the hindered potential and the angle of rotation, respectively. In the bottom of the above potential well we have

$$
\omega_{z}=4\left(V_{0} / 2 I_{z}\right)^{1 / 2}
$$

for the librational frequency [19]. By assuming $V_{0}=E_{a}$, and using equal $I_{z}$ values of present com-

[1] A. Ishikawa, Y. Ito, K. Horiuchi, T. Asaji, and D. Nakamura, J. Mol. Struct. in press (1988).

[2] Y. Furukawa and D. Nakamura, Z. Naturforsch. 41 a, 416 (1986).

[3] K. Horiuchi, R. Ikeda, and D. Nakamura, Ber. Bunsenges. Phys. Chem. 91, 1351 (1987).

[4] A. Ishikawa, K. Horiuchi, R. Ikeda, and D. Nakamura, J. Mol. Struct. in press (1988).

[5] J. W. Cooley and J. W. Tukey, Math. Comput. 19, 297 (1965).

[6] J. W. Mellor, A Comprehensive Treatise on Inorganic and Theoretical Chemistry, Vol. III, Longmans, London 1960 , p. 593.

[7] A. Sasane, T. Matuo, D. Nakamura, and M. Kubo, J. Magn. Resonance 4, 257 (1971).

[8] G. Sleater, H. Bärnighausen, and G. Brauer, Z. anorg. allg. Chem. 372, 9 (1970).

[9] J. Strähle and H. Bärnighausen, Z. Naturforsch. 25b, 1186 (1970).

[10] K. B. Dillon and T. C. Waddington, Inorg. Nucl. Chem. Lett. 14, 415 (1978). plexes, $\left(\omega_{z \mathrm{R}} / \omega_{z \mathrm{C}}\right)$ can be given as

$$
\left(\omega_{z \mathrm{R}} / \omega_{z \mathrm{C}}\right)=\left(E_{\mathrm{aR}} / E_{\mathrm{aC}}\right)^{1 / 2} .
$$

From the $E_{\mathrm{a}}$ values determined above for $\mathrm{Rb}\left[\mathrm{AuCl}_{4}\right]$ and $\mathrm{Cs}\left[\mathrm{AuCl}_{4}\right]$, the value of 1.2 was obtained for $\left(\omega_{z \mathrm{R}} / \omega_{z \mathrm{C}}\right)$. This value agrees very well with that evaluated from the analysis of the $T_{1 \mathrm{Q}}$ data obtained at low temperatures by employing the lattice vibrational model.

The foregoing results for the activation energy and the librational frequency imply that the in-plane rotational motion of the complex anion in the cesium salt is more easily activated than that of in the rubidium salt.

[11] K. R. Jeffrey and R. L. Armstrong, Phys. Rev. 174, 359 (1968).

[12] S. Alexander and A. Tzalmona, Phys. Rev. 138, A 845 (1965).

[13] A. Ishikawa, T. Asaji, R. Ikeda, and D. Nakamura, unpublished results.

[14] L. Pauling, The Nature of the Chemical Bond, 3rd ed. Cornell Univ. Press, Ithaca, New York 1960, p. 511.

[15] S. Fukada, R. Ikeda, and D. Nakamura, unpublished results.

[16] D. E. Woessner and H. S. Gutowsky, J. Chem. Phys. 39, 440 (1963).

[17] A. R. Kessel and M. A. Korchemkin, Theor. Exp. Khim. 5, 511 (1969).

[18] L. V. Jones, M. Sabir, and J. A. S. Smith, J. Phys. C: Solid State Phys. 11, 4077 (1978).

[19] J. S. Waugh and É. I. Fedin, Soviet Phys.: Solid State 4, $1633(1963)$. 